\title{
Psychometric Validation of the Persian Version of the COVID-19-Related Psychological Distress Scale and Association with COVID-19 Fear, COVID-19 Anxiety, Optimism, and Lack of Resilience
}

\author{
Nabi Nazari ${ }^{1}$ (D) Angelina Olegovna Zekiy ${ }^{2} \cdot$ Lin-Sen Feng $^{3} \cdot$ Mark D. Griffiths ${ }^{4}$
}

Accepted: 3 May 2021 / Published online: 14 May 2021

(C) The Author(s), under exclusive licence to Springer Science+Business Media, LLC, part of Springer Nature 2021

\begin{abstract}
The outbreak of the coronavirus disease-2019 (COVID-19) has resulted in a global health crisis. The COVID-19 pandemic has caused psychological distress, both in infected and uninfected individuals. The present study evaluated the validity and factor structure of the COVID-19-Related Psychological Distress Scale (CORPDS) among the general public of the Persian-speaking population. The original version of the CORPDS was translated and back-translated into Persian, followed by a pilot study. A total sample $(n=623)$ completed an online survey including the CORPDS, Fear of COVID-19 Scale (FCV-19S), Coronavirus Anxiety Scale (CAS), Kessler Psychological Distress Scale (K10), Life Orientation TestRevised (LOT-R), and Brief Resilience Scale (BRS). The Persian CORPDS had very good internal consistency and moderate test-retest reliability after 4 weeks. Maximum likelihood confirmatory factor analysis (CFA) was conducted to test construct validity $\left(\chi^{2} / \mathrm{df}=2.39\right.$, $\mathrm{CFI}=0.95, \mathrm{SRMR}=0.046, \mathrm{PCLOSE}=0.67>0.05, \mathrm{RMSEA}=0.047,90 \%$ CI $[0.038$, $0.056])$. Measurement invariance was performed across gender, including configural invariance, metric invariance, scalar invariance, and error variance invariance, and yielded further support for the two-factor structure of the CORPDS. The CORPDS correlated with the score on the $\mathrm{K} 10(r=0.46, p<0.01,95 \%$ CI $[0.43,0.48])$, CAS $(r=0.43, p<0.01,95 \%$ CI $[0.37$, $0.45]), \mathrm{FCV}-19 \mathrm{~S}(r=0.29, p<0.01,95 \%$ CI $[0.27,0.32])$, LOT-R $(r=-0.19, p<0.01$,
\end{abstract}

Nabi Nazari

Nazariirani@gmail.com

1 Department of Psychology, Faculty of Literature and Human Sciences, Lorestan University, Khorramabad, Iran

2 Department of Prosthetic Dentistry, Sechenov First Moscow State Medical University, Moscow, Russian Federation

3 The Sixth Affiliated Hospital of Kunming Medical University, (The People's Hospital of Yuxi City), Yuxi, Yunnan, China

4 International Gaming Research Unit, Psychology Division, Nottingham Trent University, Nottingham, UK 
$95 \% \mathrm{CI}[-0.15,-0.24])$ and BRS $(r=-0.56, p<0.01,95 \% \mathrm{CI}[-0.50,-0.61])$. Resilience was associated with lower psychological distress $(\beta=-0.54, S E=0.05, p<0.001)$. The findings provide evidence that CORPDS is a reliable and valid instrument for assessing psychological distress generated by COVID-19 among a healthy Persian-speaking population.

Keywords Psychological distress · COVID-19 · Anxiety · Validation · Fear of COVID-19 .

Resilience

The outbreak of the coronavirus disease-2019 (COVID-19) has resulted in a global health crisis in which more than 118 million individuals have been infected at the time of writing (Worldometer, 2021). The COVID-19 pandemic has generated psychological distress, anxiety, and fear and has disrupted people's routines (Liu et al., 2020; Taylor et al., 2020; Yang \& Ma, 2020). It is expected that the numbers of individuals affected by such psychological distress related to the pandemic will overtake those infected with it (Colizzi et al., 2020; Grover et al., 2020).

While health systems around the world have concentrated on treating the physical effects of COVID-19, elevated routine stress (e.g., occupational demands, financial worries) alongside quarantine and isolation (Brooks et al., 2020) when coupled with fear can elicit psychological distress (Holmes et al., 2020; Li et al., 2020). This can eventually lead to individuals behaving in maladaptive ways (Arpaci et al., 2020; Satici et al., 2020). Trauma researchers have shown in previous research that individuals who have a higher level of exposure to a disaster report higher psychological distress levels (Aslam \& Kamal, 2015). As soon as the COVID-19 pandemic began, research showed that the psychological distress generated led to increased domestic violence (Campbell, 2020), specific phobias, extreme fear of illness (WU et al., 2020), alcohol/tobacco abuse, and suicides (Mamun et al., 2020).

\section{Psychological Distress}

Psychological distress comprises painful mental and physical symptoms associated with normal fluctuations of mood among most individuals (American Psychological Association \& VandenBos, 2015). Psychological distress comprises maladaptive psychological functioning in the face of stressful events (Abeloff et al., 2000). Psychological distress is the independent and unique discomforting emotional state experienced by an individual in reaction to a specific stressor (e.g., objects) and may vary in intensity over time and range from common, normal feelings of vulnerability, sadness, and fears to problems that might become disabling (Ridner, 2004; Vitek et al., 2007). The psychological literature has indicated some problems regarding the assessment and measurement of psychological distress. Such distress is generally assessed utilizing highly reliable instruments concerning depression, anxiety, and stress.

For example, the 21-item Depression, Anxiety, Stress Scale (DASS-21; Lovibond \& Lovibond, 1995) and the 7-item Generalized Anxiety Disorder Scale (GAD-7; Spitzer et al., 2006) are often used for the initial screening or clinical diagnosis of anxiety, depression, and other mental symptoms. However, psychological distress can be experienced independently of depression or anxiety (Ridner, 2004; Snoek et al., 2015). Moreover, these scales are not particularly specific for assessing psychological distress among healthy individuals such as 
those uninfected by COVID-19. Compared to uninfected individuals, those who are infected by COVID-19 have been reported to be $2-3$ times more likely to report mental health symptoms with relatively high prevalence of depressive (75.0\%) and anxiety (71.0\%) symptoms (Shi et al., 2020).

Recently, Feng et al. (2020) developed the COVID-19-Related Psychological Distress Scale (CORPDS), a reliable two-factor psychometric tool that assesses the severity of psychological distress among healthy populations. Disease-specific psychometric instruments may help in the identification of problems that require immediate intervention in a clinical healthcare setting, while general distress instruments may simply identify individuals who require more in-depth screening. Also, there is a lack of information regarding the coping strategy that can reduce adverse psychological impacts of the psychological distress, fear, and anxiety generated by the COVID-19 pandemic. Poorer coping strategy is a strong predictor of the risky behaviors and suicidal ideation (Ong \& Thompson, 2019).

Resilience refers to effective (i.e., positive) adaptation to adversity (Smith \& Hanni, 2019). Resilience has been defined as a personal resource that enhances individual adaptation and positive personality characteristics (Helmreich et al., 2017). Also, optimism is an indicator of less anxiety, more stress resilience, better coping mechanisms, and reduced depression (Lam et al., 2016; Orom et al., 2015). Optimism refers to the ability for individuals to maintain positive emotion across time. Those with a positive emotional outlook appear to have a greater tendency to undertake healthy behaviors (Fredrickson \& Joiner, 2018; Pressman et al., 2019) and have a lower risk of suicidal ideation (Huffman et al., 2016).

\section{The Present Study}

The present study was conducted to validate the CORPDS among Persian-speaking populations in the context of the COVID-19 pandemic. Therefore, the present study's main objective was to evaluate the psychometric properties of the Persian CORPDS among individuals that did not have COVID-19. It was hypothesized that scores on the CORPDS would be significantly and positively associated with scores on the Kessler Psychological Distress Scale (K10; Kessler et al., 2002), Coronavirus Anxiety Scale (CAS; Lee, 2020), and Fear of COVID-19 Scale (FCV-19S; Ahorsu et al., 2020). It was also hypothesized that high scores on the CORPDS would be negatively associated with scores on the Brief Resilience Scale (BRS; Smith et al., 2008) and the Life Orientation Test-Revised (LOT-R; Scheier et al., 1994) which assesses optimism.

\section{Method}

\section{Participants}

A convenience sample of 623 participants was recruited (380 males; 243 females) aged between 19 and 54 years (mean age $=32.97$ years; $S D=9.86$ ). The demographic characteristics of the sample are shown in Table 1. The inclusion criteria were being over the age of 18 years, not being hospitalized or quarantined in the current or past viral pandemics due to a viral infection, not having (or suspect as having) COVID-19, and having fluency in the Persian language. 
Table 1 Demographic characteristics of the sample $(N=623)$

\begin{tabular}{|c|c|c|c|}
\hline Item & Value & Test & $p$ value \\
\hline \multicolumn{4}{|l|}{ Categorical variables } \\
\hline \multicolumn{4}{|l|}{ Gender, $n(\%)$} \\
\hline Women & $380(61)$ & \multirow[t]{2}{*}{$\chi^{2}=30.12$} & \multirow[t]{2}{*}{$<0.001$} \\
\hline Men & $243(39)$ & & \\
\hline \multicolumn{4}{|l|}{ Marital, $n(\%)$} \\
\hline Single & $215(34.5)$ & \multirow[t]{2}{*}{$\chi^{2}=52.79$} & \multirow[t]{2}{*}{$<0.001$} \\
\hline In a relationship & $408(65.5)$ & & \\
\hline \multicolumn{4}{|l|}{ Education, $n(\%)$} \\
\hline Primary & $115(18.5)$ & \multirow{3}{*}{$\chi^{2}=116.2$} & \multirow{3}{*}{$<0.001$} \\
\hline B.SC. & $328(52.8)$ & & \\
\hline $\mathrm{MA}$ and $\mathrm{PhD}$ & 179 (28.7) & & \\
\hline \multicolumn{4}{|c|}{ Continues variables $M(S D)$} \\
\hline Age & $32.97(9.86)$ & $t(1,621)=0.90$ & 0.35 \\
\hline CORPDS & $3.32(0.73)$ & $t(1,621)=4.10$ & $<0.001$ \\
\hline Anxiety and Fear & $3.27(0.85)$ & $t(1,621)=1.86$ & 0.06 \\
\hline Suspicion & $3.37(0.84)$ & $t(1,621)=0.84$ & 0.39 \\
\hline K10 & $27.78(6.10)$ & $t(1,621)=2.56$ & 0.01 \\
\hline FCV-19 & $2.42(0.79)$ & $t(1,621)=1.72$ & 0.06 \\
\hline CAS & $2.46(0.65)$ & $t(1,621)=1.2$ & 0.08 \\
\hline Resilience & $2.43(0.53)$ & $t(1,621)=1.42$ & 0.07 \\
\hline LOT-R & $14.94(4.01)$ & $t(1,621)=0.40$ & 0.60 \\
\hline
\end{tabular}

$n=$ frequency; $\mathrm{y}=$ years; $\mathrm{M}=$ mean; $\mathrm{SD}=$ standard deviation; $t=$ independent $\mathrm{t}$-test to compare gender, CORPDS = COVID-19 related psychological distress; $\mathrm{K} 10=$ Kessler psychological distress $;$ CAS = coronavirus anxiety scale; FCV-19S = Fear of COVID-19 scale; LOT-R = Life Orientation Test-Revised

\section{Measures}

Coronavirus Anxiety Scale (CAS; Lee, 2020) The 5-item CAS assesses dysfunctional anxiety associated with the COVID-19 (e.g., "I had trouble falling or staying asleep because I was thinking about the coronavirus"). The items are responded to on a 5-point Likert scale, ranging from 1 (strongly disagree) to 5 (strongly agree). Higher CAS scores are associated with coronavirus anxiety diagnosis, impairment, maladaptive coping, and suicidal ideation. In the present study, the scale had excellent internal validity (Cronbach's alpha $=0.90$ ).

Fear of COVID-19 Scale (FCV-19S; Ahorsu et al., 2020) The FCV-19S is a 7-item unidimensional scale that assesses fear of COVID-19. (e.g., "I am afraid of losing my life because of coronavirus-19"). Participants respond on a 5-point Likert-type scale ranging from 1 (strongly disagree) to 5 (strongly agree). The higher the score, the greater the fear of COVID-19. In the present study, the scale had very good internal validity (Cronbach's alpha = $0.82)$.

Kessler Psychological Distress Scale (K10; Kessler et al., 2002) The K10 is a 10-item unidimensional non-specific scale that assesses psychological distress among healthy populations. Responses are scored on a 5-point Likert scale ranging from 0 (none of the time) to 4 (all of the time) reflecting how much of over the past month time respondents had experienced ten symptoms, such as "feeling tired out for no good reason" and "sad or depressed". Higher scores indicate more often the participant feels symptoms of psychological distress. In the present study, the scale had very good internal validity (Cronbach's alpha $=0.85$ ). 
COVID-19-Related Psychological Distress Scale (CORPDS; Feng et al., 2020) The CORPD is a 14-item self-report scale that assesses COVID-19-related psychological distress across two domains including anxiety/fear (seven items: e.g., "I'm afraid to travel to places hard-hit by COVID-19") and suspicion (seven items: e.g., "When I see someone sneeze, I suspect s/he might be infected with COVID-19"). Responses are scored on a 5-point Likert scale ranging from 1 (strongly disagree) to 5 (strongly agree). Higher scores indicate greater distress relating to COVID-19. The psychometric properties of the CORPDS are reported in the "Results" section.

The Brief Resilience Scale (BRS; Smith et al., 2008) The 6-item BRS assesses an individual's ability to recover from stress. Three items are positively worded (e.g., "I usually come through difficult times with little trouble"), and three items are negatively worded (e.g., "I have a hard time making it through stressful events"). The items are responded to on a 5-point Likert scale ranging from 1 (strongly disagree) to 5 (strongly agree). The higher the score, the greater the resilience. In the present study, the scale had very good internal validity (Cronbach's alpha $=0.84)$.

Life Orientation Test-Revised (LOT-R; Scheier et al., 1994) The 10-item LOT-R assesses the level of optimism in a person. Three items are positively worded (e.g., "In uncertain times, I usually expect the best"), three items are negatively worded (e.g., "If something can go wrong for me, it will"), and four items are filter items only (e.g., "It's easy for me to relax"). The items are responded to on a 5-point Likert scale ranging from 0 (strongly disagree) to 4 (strongly agree). Higher scores indicate greater people's expectations regarding the favorability of future outcomes. In the present study, the scale had very good internal validity (Cronbach's alpha= $0.85)$.

\section{Procedure}

Ethics The study, including all assessments and procedures for the study, was reviewed by the National Institute for Medical Research and Development and Institutional Human Research Ethics Committee. The first author's Institutional Review Board also approved the research protocol to ensure participant confidentiality, sampling, and obtaining informed consent. Permission to translate and validate the CORPDS was also granted by the first author of the original scale.

Scale Translation The translation and cultural adaptation of the CORPDS were performed according to guidelines suggested by Beaton et al. (2000). In the first stage, two Persian translators independently translated the CORPDS from English to Persian. One of the translators was informed and aware of the research concepts, while the other translator had no knowledge and background of the research concepts. Backward Persian-to-English translation of the scale was then carried out by a native English translator. To obtain a consensus version, an expert committee evaluated both versions to synthesize a consensual version. Then, a native English translator performed a backward translation of the consensual version. The expert committee's role was to consolidate all the versions of the questionnaire and develop the penultimate version for field testing during the pretest phase, which was subsequently compared with the original version. No significant changes were needed. 
Pilot Study A pilot study was conducted with 30 participants selected from the target population to verify the feasibility and comprehension of the web-based survey. Respondent debriefing was undertaken to identify actual and potential linguistic barriers, item difficulties, and ambiguity of the survey items. The median response time was $20 \mathrm{~min}$.

Participant Recruitment The study was conducted during the COVID-19 pandemic (June to August 2020) so the data were collected online because face-to-face data collection was not possible. Therefore, a link to an online survey was distributed on approximately 30 Persianlanguage online forums including the social media platforms (e.g., WhatsApp, Instagram). The sample size of 623 was between 500 and 1000 participants which is considered a very good size for validation studies (Comrey \& Lee, 2013).

\section{Data Analysis}

There were no missing values in the assessed variables, and no imputation method was implemented. Univariate normality was checked by examining the skewness and kurtosis values and those within $<|1|$ suggest absence of severe violations of normality. Variance inflation factor (VIF) was utilized to examine the multicollinearity issue $(1<\mathrm{VIF}<3)$ (Hair et al., 2018). Values of skewness and kurtosis were within $<|1|$ that suggest absence of severe violations of normality (Tabachnick \& Fidell, 2014) (Tabachnick \& Fidell, 2014).

A maximum likelihood confirmatory factor analysis (CFA) was conducted using AMOS 24 on the total sample. The following indices were considered as an excellent fitting model (Hu \& Bentler, 1999): $1<\chi^{2} / d f<3$, comparative fit index $(\mathrm{CFI})>0.95$, root mean square error of approximation (RMSEA) $<0.06$, and standardized root mean square residual $(\mathrm{SRMR})<0.06$. Subsequently, to further examine the changes in the model fitting index, measurement invariance was tested within the framework of multi-group CFA (Byrne, 2017; Kline, 2016). Measurement invariance is important to assess the psychometric equivalence of a construct across different groups. A research question that requires a different CFA approach is: "Does the scale perform differently for one population than another?"(Schumacker \& Lomax, 2016; Byrne, 2017). The total sample divided two groups regarding gender. First, the two-factor model for the groups (male, female) was evaluated. Given the model fitted well for both groups (see "Results" section), measurement invariance was performed. This included configural invariance, metric invariance, scalar invariance, and error variance invariance across gender for the CORPDS. A change in CFA $(\triangle \mathrm{CFI})<0.01)$, a change in TLI $(\triangle \mathrm{TLI})<0.01$, and a change in RMSEA ( $\triangle$ RMSEA) $<0.015$ indicate a non-invariance between groups (Chen, 2007; Cheung \& Rensvold, 2002).

Cronbach's alpha reliability coefficient and composite reliability (CR) were performed to evaluate CORPDS reliability. The Cronbach alpha if item deleted values and corrected item correlation values are shown in Table 2. To test-retest evaluate reliability, an intraclass correlation coefficient (ICC) was generated by ICC $(N=94)$ after 4 weeks. Convergent validity was tested utilizing average extracted variance (AVE of .5 or higher and lower than CR) (Henseler et al., 2016). Also, discriminate validity is achieved when AVE value is greater than the maximum shared squared variance (MSV).

To establish the criterion-related validity, convergent validity, and discriminant validity of the CORPDS and its two subscales, correlation analyses were performed using the scores on the K10, CAS, FCV-19S, and BRS. The magnitude of Pearson correlations $(r)$ vary. 
Table 2 Item statistics

\begin{tabular}{lllllllll}
\hline $\begin{array}{l}\text { Item } \\
\text { number }\end{array}$ & Dimension & $M$ & $S D$ & Skewness & Kurtosis & $\begin{array}{l}\text { Corrected item-total } \\
\text { correlation }\end{array}$ & $\begin{array}{l}\text { Cronbach's alpha if } \\
\text { item deleted }\end{array}$ & VIF \\
\hline 1 & Anxiety/fear & 3.41 & 1.16 & 0.39 & 0.76 & 0.55 & 0.870 & 1.61 \\
3 & Anxiety/fear & 3.40 & 1.18 & 0.16 & 0.71 & 0.56 & 0.870 & 1.64 \\
4 & Anxiety/fear & 3.19 & 1.24 & 0.30 & 0.70 & 0.60 & 0.867 & 1.89 \\
6 & Anxiety/fear & 3.17 & 1.24 & 0.60 & 0.42 & 0.49 & 0.873 & 1.53 \\
7 & Anxiety/fear & 3.14 & 1.23 & 0.27 & 0.73 & 0.62 & 0.867 & 1.85 \\
8 & Anxiety/fear & 3.26 & 1.11 & 0.33 & 0.69 & 0.53 & 0.871 & 1.6 \\
11 & Anxiety/fear & 3.35 & 1.15 & 0.36 & 0.64 & 0.46 & 0.869 & 1.55 \\
2 & Suspicion & 3.46 & 1.05 & 0.47 & 0.41 & 0.57 & 0.869 & 1.70 \\
5 & Suspicion & 3.44 & 1.13 & 0.46 & 0.51 & 0.58 & 0.869 & 1.62 \\
9 & Suspicion & 3.36 & 1.23 & 0.38 & 0.83 & 0.56 & 0.868 & 1.74 \\
10 & Suspicion & 3.29 & 1.15 & 0.44 & 0.36 & 0.59 & 0.873 & 1.96 \\
12 & Suspicion & 3.39 & 1.24 & 0.45 & 0.43 & 0.49 & 0.871 & 1.96 \\
13 & Suspicion & 3.25 & 1.23 & 0.55 & 0.43 & 0.50 & 1.63 \\
14 & Suspicion & 3.39 & 1.12 & 0.56 & 0.22 & 0.54 & & \\
\hline
\end{tabular}

$\mathrm{M}=$ mean; $\mathrm{SD}=$ standard deviation; $\mathrm{VIF}=$ variance inflation factor

Correlations of $0.10,0.30$, and 0.50 correspond to small, medium, and large Cohen's $d$ effect sizes, respectively (Cohen, 1992). Finally, structural equation modeling (SEM) was used to examine the effects of resilience and optimism on CORPDS scores, CAS scores, and FCV-19S scores. These values signify approximately moderate $\left(f^{2} \geq 0.15\right)$ to large $\left(f^{2} \geq 0.35\right)$ effect sizes, according to Cohen's guidelines (Cohen, 1988). The data were analyzed using SPSS (version 25, SPSS Inc., Chicago, IL) and AMOS (version 24, IBM).

\section{Results}

The demographic characteristics of the sample are shown in Table 1. Significantly more participants were well educated $\left(\chi^{2}=116.2, p<0.001\right)$ and female $\left(\chi^{2}=30.12, p<0.001\right)$. Females had statistically significant higher scores on the CORPDS $(M=3.36, S D=0.72)$ than males $(M=3.08, S D=0.87)(t[621]=4.10, p<0.001$, Cohen's $d=0.35,95 \%[0.19,0.51])$. Also, females had statistically significant higher scores on the $\mathrm{K} 10(M=28.97, S D=6.57)$ than males $(M=27.64, S D=6.28)(t[621]=2.57, p=0.01$, Cohen's $d=0.21,95 \%[0.05$, $0.37])$. There were no other gender differences. The VIF for 14 items were in satisfactory range $(1<V I F<3)$. The corrected item-total correlations were all well above the recommended level of 0.3 (see Table 2).

Maximum likelihood confirmatory factor analysis (CFA) was conducted to test construct validity. The two-factor model fitted well in the total sample $\left(\chi^{2} / \mathrm{df}=2.39, \mathrm{CFI}=0.95\right.$, $\mathrm{SRMR}=0.046, \mathrm{PCLOSE}=0.67>0.05, \mathrm{RMSEA}=0.047,90 \%$ CI $[0.038,0.056]$; see Fig. 1). The CFAs for the male and female samples were generated to evaluate the fit indices. ML CFA for male sample $(n=243)$ yielded a good fit to the model $\left(\chi^{2} / \mathrm{df}=1.52, \mathrm{CFI}=0.968\right.$, SRMR $=0.047$, PCLOSE $=0.94>0.05$, RMSEA $=0.037,90 \%$ CI $[0.022,0.050])$. The CFA for the female sample $(n=380)$ also yielded a good fit to the model $\left(\chi^{2} / \mathrm{df}=2.01, \mathrm{CFI}=0.966\right.$, $\mathrm{SRMR}=0.044$, PCLOSE $=0.41>0.05$, RMSEA $=0.036,90 \%$ CI $[0.044,0.057])$. Measurement invariance was performed across gender, including configural invariance, metric invariance, scalar invariance, and error variance invariance $(\triangle T L I<.01, \triangle C F I<.01$; see Table 3$)$. 


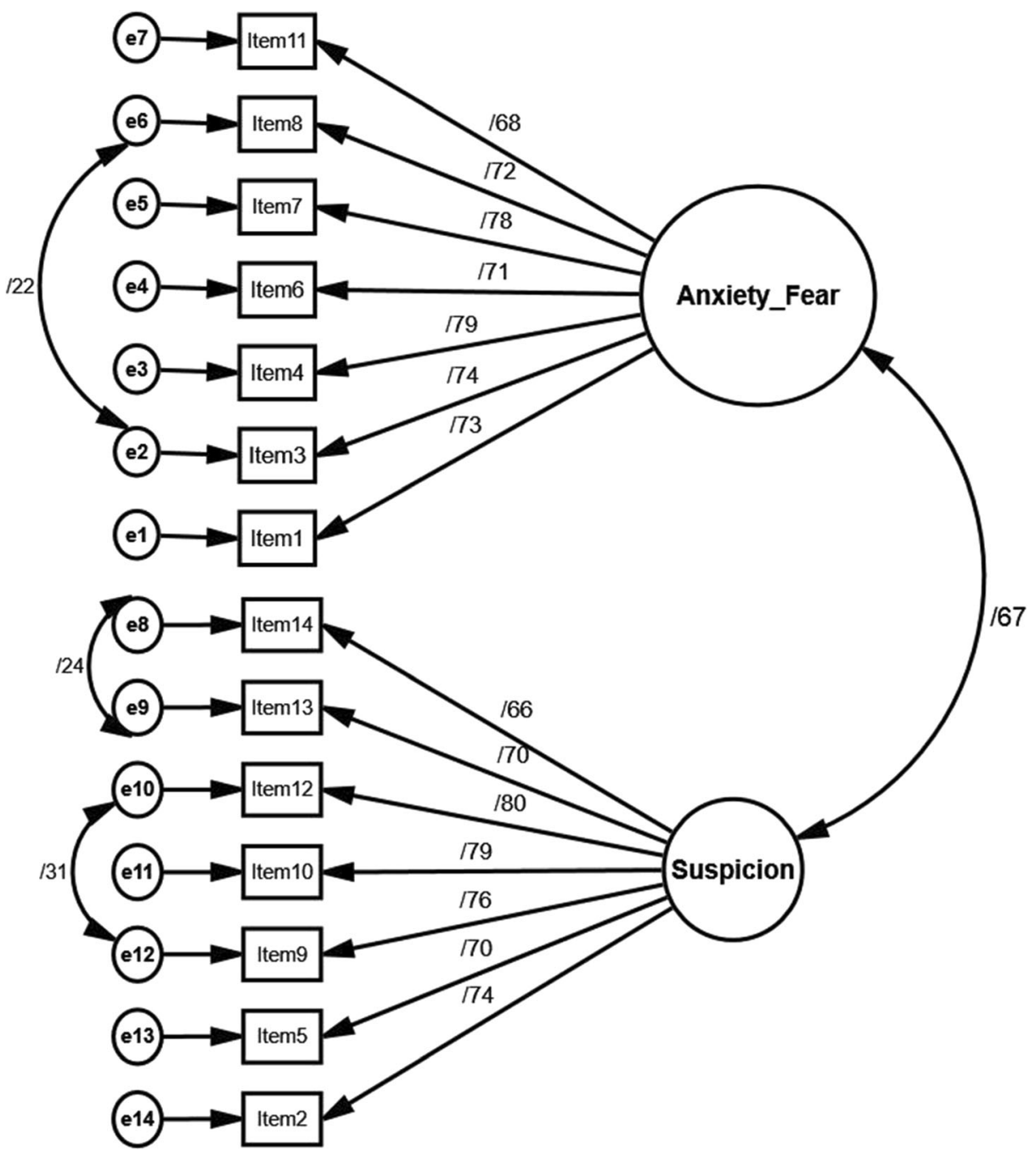

Fig. 1 Structural equation model of two-factor CORPDS $(N=623)$

The Cronbach alpha of the scale indicated very good internal reliability $(\alpha=0.88)$. Also, the CR value was excellent (0.90). The Cronbach alpha if item deleted values and corrected item correlation values are shown in Table 2. ICC evaluated the test-retest reliability. After 4

Table 3 Invariance measurement $(\mathrm{N}=623)$

\begin{tabular}{llllllll}
\hline Type of invariance & $\chi^{2} / d f$ & CFI & $\Delta$ CFI & TLI & $\Delta$ TLI & AIC & RMSEA 90\% [CI] \\
\hline Configural & 1.570 & 0.973 & - & 0.965 & - & 414.9 & $0.030[0.022,0.038]$ \\
Gender weak (metric) & 1.508 & 0.973 & 0.000 & 0.969 & -0.004 & 400.3 & $0.029[0.021,0.036]$ \\
Gender strong (scalar) & 1.497 & 0.972 & 0.001 & 0.969 & -0.004 & 391.2 & $0.028[0.022,0.035]$ \\
Gender strict & 1.573 & 0.967 & 0.006 & 0.965 & 0.000 & 402.9 & $0.030[0.023,0.037]$ \\
\hline
\end{tabular}

CFI = comparative fit index; TLI = Tucker-Lewis index; RMSEA = root mean square error of approximation $(\mathrm{RMSEA}) ; \mathrm{CI}=$ confidence interval. $\mathrm{AIC}=$ Akaike information criterion 
Table 4 Sub-scale validity analysis

\begin{tabular}{llllllll}
\hline Dimension & $\alpha$ & CR & AVE & MSV & MaxR(H) & Anxiety_Fear & Suspicion \\
\hline Anxiety/fear & 0.84 & 0.892 & 0.542 & 0.446 & 0.895 & 0.736 & 0.739 \\
Suspicion & 0.87 & 0.893 & 0.546 & 0.446 & 0.898 & 0.668 & 0.78 \\
\hline
\end{tabular}

Note: $\mathrm{AVE}>.50 ; \mathrm{AVE}>\mathrm{MSV}$

$\mathrm{CR}=$ composite reliability; $\mathrm{AVE}=$ average variance extracted; $\alpha=$ Cronbach alpha coefficient; $\mathrm{MSV}=$ maximum shared squared variance; $\operatorname{Max}(\mathrm{H})=$ maximum reliability

$* *$ Correlation is significant at the $p<0.01$ level (2-tailed)

weeks of the original validation study, the survey was re-sent to half of the participants $(n=$ 300) who were randomly selected by the random number generator. Of these, 94 surveys were returned. In terms of consistency, the ICC was 0.74 with $95 \%$ CI $[0.62,0.82]$ for the single measure. The subscale validity is shown in Table 4. The Cronbach coefficients and composite reliability were calculated for each dimension and the values were satisfactory. Convergent validity was tested utilizing average extracted variance (AVE) and was 0.65 for the CORPDS. Also, AVE was calculated for each dimension.

The full correlation matrix between all the variables is presented in Table 5. As for criterion-related validity, the score on the CORPDS positively correlated with the scores on the $\mathrm{K} 10(r=0.46, p<0.01,95 \%$ CI $[0.43,0.48])$, CAS $(r=0.43, p<0.01,95 \%$ CI [0.37, $0.45])$, and FCV-19S $(r=0.29, p<0.01,95 \% \mathrm{CI}[0.27,0.32])$. As for discriminant validity, the score on the CORPDS negatively correlated with the score on the BRS $(r=-0.56, p<0.01$, $95 \% \mathrm{CI}[-0.50,-0.61])$ and LOT-R $(r=-0.19, p<0.01,95 \%$ CI $[-0.15,-0.24])$. The anxiety/fear subscale score of the CORPDS correlated with the CAS score $(r=0.52,95 \% \mathrm{CI}$ $[0.46,0.57], p<.01)$ and the FCV-19S score $(r=0.14,95 \%$ CI $[0.06,0.22], p<0.01)$. The suspicion subscale score of the CORPDS correlated with the CAS score $(r=0.22,95 \% \mathrm{CI}$ $[0.14,0.22], p<0.01)$, and the FCV-19S score $(r=0.57,95 \%$ CI $[0.51,0.62], p<0.01)$.

The SEM analysis results showed an excellent fit $\left(\chi^{2} / d f=1.07, p<0.001, \mathrm{CFI}=1\right.$, TLI $=$ 0.998, SRMR $=0.02$, RMSEA $=0.011,90 \%$ CI [0.001, 0.08]). Resilience was significantly associated with lower psychological distress $\left(\beta=-0.54, S E=0.05, p<0.001\right.$ Cohen's $f^{2}=$ 0.92 , with $95 \%$ CI $[0.62,1.28])$, lower CAS scores $(\beta=-0.30, S E=0.048, p<0.001$ Cohen's $f^{2}=0.16$, with $95 \%$ CI $\left.[0.06,0.32]\right)$, and lower fear of COVID-19 scores $(\beta=-0.19, S E=$ $0.07, p<0.001$; Cohen's $f^{2}=0.10$, with $95 \%$ CI $[0.04,0.18]$ ). Also, optimism was

Table 5 Correlation matrix for SEM variables

\begin{tabular}{lllllll}
\hline Measure & CORPDS & CAS & FCV-19S & BRS & LOT-R & CORPDS Anxiety/Fear \\
\hline CAS & $0.44 * *$ & & & & & \\
FCV-19S & $0.30^{* *}$ & $0.10^{*}$ & & & & \\
BRS & $-0.56^{* *}$ & $-0.31^{* *}$ & $-0.22^{* *}$ & & & \\
LOT-R & $-0.19 * *$ & $-0.12^{*}$ & $-0.18^{* *}$ & $0.23^{* *}$ & & \\
CORPDS Anxiety/Fear & $0.86^{* *}$ & $0.52^{* *}$ & $14^{* *}$ & $-0.51^{* *}$ & $-0.08^{*}$ & \\
CORPDS Suspicion & $0.79 * *$ & $0.22^{* *}$ & $0.57^{* *}$ & $-0.45^{* *}$ & $-0.20^{* *}$ & $0.49 * *$ \\
\hline
\end{tabular}

CORPDS = COVID-19-Related Psychological Distress Scale; CAS = Coronavirus Anxiety Scale; FCV-19 = Fear of COVID-19 Scale, BRS = Brief Resilience Scale, LOT-R = Life Orientation Test-Revised

$* *$ Correlation is significant at the $p<0.01$ level (2-tailed)

*Correlation is significant at the $p<0.05$ level (2-tailed) 


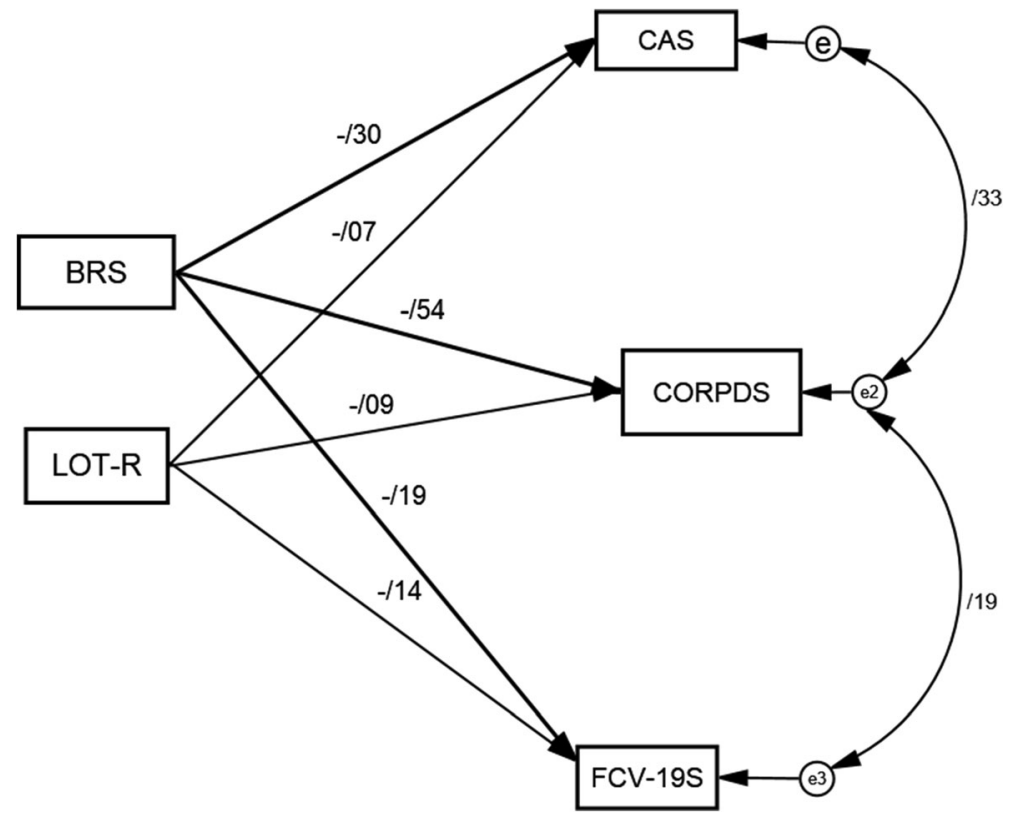

Fig. 2 Structural equation model of the coping strategies $(N=623)$. BRS $=$ Brief Resilience Scale, LOT-R $=$ Life Orientation Test-Revised, CAS = Corona Anxiety scale, CORPDS = COVID-19-Related Psychological Distress Scale, FCV-19S = Fear of COVID-19 Scale

significantly associated with lower fear of COVID-19 scores $(\beta=-0.14, S E=0.04, p<0.001$ Cohen's $f^{2}=0.07$, with $95 \%$ CI $[0.02,0.14]$ ) (see Fig. 2).

\section{Discussion}

For the WHO, the COVID-19 is much more than a medical challenge. There is also a mental health crisis with possible long-lasting and profound adverse consequences. Therefore, understanding the specific pandemic's effects on psychological health is of great importance (Wang et al., 2020; Pfefferbaum \& North, 2020). Therefore, the present study was conducted to evaluate the reliability, validity, and factor structure of the Persian CORPDS. Also, the study investigated resilience and optimism associations on three specific COVID-19 scales (COVID19-Related Psychological Distress Scale, Coronavirus Anxiety Scale, and Fear of COVID-19 Scale) to gain more specific insights regarding the psychological consequences of the pandemic.

The results demonstrated that the CORPDS is a valid and reliable instrument to psychological distress related to COVID-19 among the Persian-speaking general population. The evaluation of internal consistency, tested by Cronbach's alpha and CR, demonstrated that the CORPDS had very good reliability. The results also confirmed that that the CORPDS has a two-factor structure, and therefore, the findings were consistent with the original psychometric validation study. Also, the measurement invariance yielded further support for the two-factor structure which was not evaluated in the original study.

To evaluate criterion-related validity, convergent validity, and discriminant validity, the CORPDS (and its subscales) was correlated against the scores for psychological distress 
(K10), fear of COVID-19 (FCV-19S), COVID-19 anxiety (CAS), and BRS (resilience). Findings demonstrated significant positive (moderate to high) correlations between scores on the CORPDS and scores on the K10, CAS, and FCV-19S which indicate acceptable criterionrelated validity and convergent validity. The significant negative correlation between the score on the CORPDS and the score on the BRS suggested good discriminant validity.

\section{Practical Implications}

Assessment Consideration As previously noted, there are measurement issues in regard to the psychological distress. In line with numerous studies (e.g., Badahdah et al., 2020; Qiu et al., 2020; Fernández, et al., 2020, Nazari \& Griffiths, 2020), females reported more psychological problems than males in relation to the psychological consequence of the COVID-19 pandemic. In our sample, females had significantly higher scores on the K10 (psychological distress) and CORPDS compared to males, among the general population sample. There were no gender differences in scores on the CAS. Although both the CAS and CORPDS were developed for response to COVID-19 specifically, the CAS was developed among participants that already had clinical diagnosis of the anxiety symptoms during the pandemic whereas the CORPDS was developed among healthy participants. These findings potentially indicate the effectiveness of a specific measure for screening for psychological distress among healthy people who are psychologically affected by the pandemic but not to the extent that they have a clinical diagnosis. In recent years, epidemiological studies have employed short dimensional scales to assess and monitor the extent of psychological distress in the general healthy community as proxy measures for early diagnosis.

Treatment Considerations The SEM analysis showed a significant negative correlation between resilience and scores on the CORPDS, CAS, and FCV-19S. The SEM analysis also showed a significant negative correlation between optimism and scores on the FCV19. Resilience has been found to be a negative predictor of psychological distress in stressful condition (Harker et al., 2016). More specifically, in an unexpected crisis, resilience refers to an individual's ability to continue functioning and to readjust from adversity (Bryce et al., 2020; Chen et al., 2016). According neuro-affective science research, a greater ability to savor positive effects can promote quality of life (Davidson, 2015). Consequentially, the ability to bounce back quickly from negative events inevitably facilitates the maintenance of positive affect and the ability to maintain positive affect inevitably facilitates bouncing back from negative events (Kesebir et al., 2019). Also, both optimism and resilience were associated with lower FCV-19S scores. Persistence of the positive emotion may be an effective coping strategy to reduce the risk of depression in traumatic situations in which individuals' resilient abilities are critical (Fredrickson et al., 2003; Laird et al., 2019).

Collectively, regarding relationship between resilience with COVID-19 psychological distress, COVID-19 anxiety, and fear COVID-19, treatment approaches that focus on increasing resilience (e.g., resilience-enhancing interventions) can be implemented to enhance preventive efforts, to promote well-being, and to reduce negative mental health (Horn \& Feder, 2018). Resilience is a protective factor in disaster recovery. Resilience can help overcome negative psychological problems in high stressful situations or traumatic events (Cénat \& Derivois, 2014; Mohammadinia et al., 2019). The results of the present study suggest that 
individuals with lower levels of resilience may be more vulnerable to negative pandemic consequences such as fear of COVID-19. Therefore, evaluation of the resiliency resources and traits provides valuable information for healthcare staff (e.g., psychiatrists, psychologists, caregivers) concerning individuals' psychological states.

\section{Limitations}

The findings of the present study should be interpreted in light of several limitations. To minimize infection risk via the traditional survey method, online data collection was utilized. Online data collection may have limited the participation of specific relevant population groups (e.g., disadvantaged groups such as those in poverty who may not have internet access). Therefore, the data cannot represent these groups' views, affecting the study findings' generalizability. However, online data collection tends to provide more honest and truthful responses than those utilizing offline methods (Griffiths, 2010). Another limitation of the present study was that the validation of the CORPDS and its dimensions relied entirely on self-report measures, which are subject to various methods biases.

\section{Conclusion}

Despite such limitations, the findings provide evidence that CORPDS is a reliable and valid instrument for assessing psychological distress related to COVID-19. The Persian CORPDS can be used in the prevention and clinical research in Persian-speaking countries. The findings also have important implications for clinical assessment and treatment. For instance, CORPDS can be considered as an efficient additional clinical instrument to assess psychological distress. Psychological distress can be an indicator of incipient emotional disorders (e.g., depression, anxiety disorder), schizophrenia, somatization disorder, or other clinical conditions. Consequently, individuals experiencing psychological distress require effective and targeted intervention. Specific distress scales are often utilized to provide early indications of individuals in need of further assessment for anxiety and depression disorders. Understanding whether distress causes specific health outcomes over time may guide the discussion between patients and their healthcare teams (Barry et al., 2020). Scores on specific distress scales yield the largest statistically and the clinically significant difference compared with traditional measures of general depression and anxiety symptoms (Wichman et al., 2011). Also, evaluation of the resiliency resources can be helpful in planning psychological treatment programs. The findings of the present study suggest that resilience can be a clinically useful targeted construct in the use of psychological interventions during the pandemic and post-pandemic period.

Data Availability The data that support the findings of this study are available on request from the corresponding author.

\section{Declarations}

Competing Interests The authors declare no conflicts of interest. 


\section{References}

Abeloff, M. D., Armitage, J. O., Lichter, A. S., \& Niederhuber, J. E. (2000). Clinical oncology (2nd ed.). Churchill Livingstone.

Ahorsu, D. K., Lin, C. Y., Imani, V., Saffari, M., Griffiths, M. D., \& Pakpour, A. H. (2020). The Fear of COVID19 Scale: development and initial validation. International Journal of Mental Health and Addiction. Advance online publication. https://doi.org/10.1007/s11469-020-00270-8.

American Psychological Association, \& VandenBos, G. R. (2015). APA dictionary of psychology. American Psychological Association.

Arpaci, I., Karataş, K., \& Baloğlu, M. (2020). The development and initial tests for the psychometric properties of the COVID-19 Phobia Scale (C19P-S). Personality and Individual Differences, 164, 110108. https://oi. org/10.1016/j.paid.2020.110108.

Aslam, N., \& Kamal, A. (2015). Coping strategies as a predictors of psychological distress and post traumatic growth among flood affected individuals. Journal of Alcoholism \& Drug Dependence, 03(01). https://doi. org/10.4172/2329-6488.1000181.

Badahdah, A. M., Khamis, F., \& Mahyijari, N. A. (2020). The psychological well-being of physicians during COVID-19 outbreak in Oman. Psychiatry Research, 289, 113053. https://doi.org/10.1016/j.psychres.2020. 113053.

Barry, V., Stout, M. E., Lynch, M. E., Mattis, S., Tran, D. Q., Antun, A., Ribeiro, M. J., Stein, S. F., \& Kempton, C. L. (2020). The effect of psychological distress on health outcomes: A systematic review and metaanalysis of prospective studies. Journal of Health Psychology, 25(2), 227-239. https://doi.org/10.1177/ 1359105319842931.

Beaton, D. E., Bombardier, C., Guillemin, F., \& Ferraz, M. B. (2000). Guidelines for the process of cross-cultural adaptation of self-report measures. Spine, 25(24), 3186-3191. https://doi.org/10.1097/00007632200012150-00014.

Brooks, S. K., Webster, R. K., Smith, L. E., Woodland, L., Wessely, S., Greenberg, N., \& Rubin, G. J. (2020). The psychological impact of quarantine and how to reduce it: rapid review of the evidence. The Lancet, 395(10227), 912-920. https://doi.org/10.1016/S0140-6736(20)30460-8.

Bryce, C., Ring, P., Ashby, S., \& Wardman, J. K. (2020). Resilience in the face of uncertainty: early lessons from the COVID-19 pandemic. Journal of Risk Research. Advance online publication., 23, 880-887. https://doi. org/10.1080/13669877.2020.1756379.

Byrne, B. M. (2017). Structural equation modeling with AMOS: basic concepts, applications, and programming (3rd ed.). Routledge.

Campbell, A. M. (2020). An increasing risk of family violence during the Covid-19 pandemic: strengthening community collaborations to save lives. Forensic Science International: Reports, 2, 100089. https://doi.org/ 10.1016/j.fsir.2020.100089.

Cénat, J. M., \& Derivois, D. (2014). Psychometric properties of the Creole Haitian version of the Resilience Scale amongst child and adolescent survivors of the 2010 earthquake. Comprehensive Psychiatry, 55(2), 388-395. https://doi.org/10.1016/j.comppsych.2013.09.008.

Chen, F. F. (2007). Sensitivity of goodness of fit indexes to lack of measurement invariance. Structural Equation Modeling, 14(3), 464-504. https://doi.org/10.1080/10705510701301834.

Chen, C. (2016). The role of resilience and coping styles in subjective well-being among Chinese university students. The Asia-Pacific Education Researcher, 25(3), 377-387. https://doi.org/10.1007/s40299-0160274-5.

Cheung, G. W., \& Rensvold, R. B. (2002). Evaluating goodness-of-fit indexes for testing measurement invariance. Structural Equation Modeling, 9(2), 233-255. https://doi.org/10.1207/s15328007sem0902_5.

Cohen, J. (1988). Statistical power analysis for the behavioral sciences. Lawrence Erlbaum Associates.

Cohen, J. (1992). A power primer. Psychological Bulletin, 112(1), 155-159. https://doi.org/10.1037/0033-2909. 112.1.155.

Colizzi, M., Bortoletto, R., Silvestri, M., Mondini, F., Puttini, E., Cainelli, C., Gaudino, R., Ruggeri, M., \& Zoccante, L. (2020). Medically unexplained symptoms in the times of Covid-19 pandemic: a case-report. Brain, Behavior, \& Immunity - Health. Advance online pubication, 5, 100073. https://doi.org/10.1016/j. bbih.2020.100073.

Comrey, A. L., \& Lee, H. B. (2013). A first course in factor analysis (2nd ed.). Hoboken, NJ: Taylor and Francis.

Davidson, R. J. (2015). Comment: Affective chronometry has come of age. Emotion Review, 7, 368-370. https:// doi.org/10.1177/1754073915590844.

Feng, L., Dong, Z., Yan, R., Wu, X., Zhang, L., \& Ma, J. (2020). Psychological distress in the shadow of the COVID-19 pandemic: preliminary development of an assessment scale. Psychiatry Research, 291, 113202. https://doi.org/10.1016/j.psychres.2020.113202. 
Fernández, R. S., Crivelli, L., Guimet, N. M., Allegri, R. F., \& Pedreira, M. E. (2020). Psychological distress associated with COVID-19 quarantine: Latent profile analysis, outcome prediction and mediation analysis. Journal of affective disorders, 277, 75-84. https://doi.org/10.1016/j.jad.2020.07.133.

Fredrickson, B. L., \& Joiner, T. (2018). Reflections on positive emotions and upward spirals. Perspectives on Psychological Science, 13(2), 194-199. https://doi.org/10.1177/1745691617692106.

Fredrickson, B. L., Tugade, M. M., Waugh, C. E., \& Larkin, G. R. (2003). What good are positive emotions in crises? A prospective study of resilience and emotions following the terrorist attacks on the United States on September 11th, 2001. Journal of Personality and Social Psychology, 84(2), 365-376. https://doi.org/10. 1037//0022-3514.84.2.365.

Griffiths, M. D. (2010). The use of online methodologies in data collection for gambling and gaming addictions. International Journal of Mental Health and Addiction, 8, 8-20. https://doi.org/10.1007/s11469-009-9209-1.

Grover, S., Dua, D., Sahoo, S., Mehra, A., Nehra, R., \& Chakrabarti, S. (2020). Why all COVID-19 hospitals should have mental health professionals: the importance of mental health in a worldwide crisis! Asian Journal of Psychiatry, 51, 102147. https://doi.org/10.1016/j.ajp.2020.102147.

Hair, J. F., Babin, B. J., Anderson, R. E., \& Black, W. C. (2018). Multivariate Data Analysis. In Multivariate data analysis (8th ed.). Cengage Learning. https://doi.org/10.1002/9781119409137.ch4.

Harker, R., Pidgeon, A. M., Klaassen, F., \& King, S. (2016). Exploring resilience and mindfulness as preventative factors for psychological distress burnout and secondary traumatic stress among human service professionals. Work, 54(3), 631-637. https://doi.org/10.3233/wor-16231.

Helmreich, I., Kunzler, A., Chmitorz, A., König, J., Binder, H., Wessa, M., \& Lieb, K. (2017). Psychological interventions for resilience enhancement in adults. The Cochrane Database of Systematic Reviews, 2017(2), CD012527. https://doi.org/10.1002/14651858.CD012527.

Henseler, J., Hubona, G., \& Ray, P. A. (2016). Using PLS path modeling in new technology research: updated guidelines. Industrial Management \& Data Systems, 116(1), 2-20. https://doi.org/10.1108/imds-09-20150382 .

Holmes, E. A., O’Connor, R. C., Perry, V. H., Tracey, I., Wessely, S., Arseneault, L., ... Bullmore, E. (2020). Multidisciplinary research priorities for the COVID-19 pandemic: a call for action for mental health science. The Lancet Psychiatry, 7(6), 547-560. https://doi.org/10.1016/s2215-0366(20)30168-1.

Horn, S. R., \& Feder, A. (2018). Understanding resilience and preventing and treating PTSD. Harvard Review of Psychiatry, 26(3), 158-174. https://doi.org/10.1097/hrp.0000000000000194.

Hu, L. T., \& Bentler, P. M. (1999). Cutoff criteria for fit indexes in covariance structure analysis: conventional criteria versus new alternatives. Structural Equation Modeling, 6(1), 1-55. https://doi.org/10.1080/ 10705519909540118.

Huffman, J. C., Boehm, J. K., Beach, S. R., Beale, E. E., DuBois, C. M., \& Healy, B. C. (2016). Relationship of optimism and suicidal ideation in three groups of patients at varying levels of suicide risk. Journal of Psychiatric Research, 77, 76-84. https://doi.org/10.1016/j.jpsychires.2016.02.020.

Kesebir, P., Gasiorowska, A., Goldman, R., Hirshberg, M. J., \& Davidson, R. J. (2019). Emotional Style Questionnaire: a multidimensional measure of healthy emotionality. Psychological Assessment, 31(10), 1234-1246. https://doi.org/10.1037/pas0000745.

Kessler, R. C., Andrews, G., Colpe, L. J., Hiripi, E., Mroczek, D. K., Normand, S. L. T., et al. (2002). Short screening scales to monitor population prevalences and trends in non-specific psychological distress. Psychological Medicine, 32(6), 959-976. https://doi.org/10.1017/S0033291702006074.

Kline, R. B. (2016). Principles and practices of structural equation modelling. In T. D. Little (Ed.), Methodology in the social sciences (4th ed., pp. 394-422). Guilford Press.

Laird, K. T., Krause, B., Funes, C., \& Lavretsky, H. (2019). Psychobiological factors of resilience and depression in late life. Translational Psychiatry, 9(1), 1-18. https://doi.org/10.1038/s41398-019-0424.

Lam, W. W., Yeo, W., Suen, J., Ho, W. M., Tsang, J., Soong, I., Yau, T. K., Wong, K. Y., Sze, W. K., Ng, A. W., Kwong, A., Suen, D., Fong, D., Ho, S., \& Fielding, R. (2016). Goal adjustment influence on psychological well-being following advanced breast cancer diagnosis. Psycho-Oncology, 25(1), 58-65. https://doi.org/10.1002/pon.3871.

Lee, S. A. (2020). Coronavirus anxiety scale: a brief mental health screener for COVID-19 related anxiety. Death Studies, 44(7), 393-401. https://doi.org/10.1080/07481187.2020.1748481.

Li, Y., Wang, Y., Jiang, J., Valdimarsdóttir, U. A., Fall, K., Fang, F., Song, H., Lu, D., \& Zhang, W. (2020). Psychological distress among health professional students during the COVID-19 outbreak. Psychological Medicine. Advance online publication, 1-3. https://doi.org/10.1017/S0033291720001555.

Liu, Y., Cao, L., Li, X., Jia, Y., \& Xia, H. (2020). Awareness of mental health problems in patients with coronavirus disease 19 (COVID-19): a lesson from an adult man attempting suicide. Asian Journal of Psychiatry, 51, 2018-2020. https://doi.org/10.1016/j.ajp.2020.102106. 
Lovibond, P. F., \& Lovibond, S. H. (1995). The structure of negative emotional states: comparison of the Depression Anxiety Stress Scales (DASS) with the Beck Depression and Anxiety Inventories. Behaviour Research and Therapy, 33, 335-343. https://doi.org/10.1016/0005-7967(94)00075-u.

Mamun, M. A., Chandrima, R. M., \& Griffiths, M. D. (2020). Mother and son suicide pact due to covid-19related online learning issues in Bangladesh: an unusual case report. International Journal of Mental Health and Addiction. Advance online publication. https://doi.org/10.1007/s11469-020-00362-5.

Mohammadinia, L., Ebadi, A., Malekafzali, H., Allen, K. A., \& Sharif Nia, H. (2019). The design and psychometric evaluation of the Adolescents' Resilience in Disaster Tool (ARDT-Q37): a mixed method study. Heliyon, 5(7), e02019. https://doi.org/10.1016/j.heliyon.2019.e02019.

Nazari, N., \& Griffiths, M. D. (2020). Psychometric validation of the Persian version of the Emotional Style Questionnaire. Current psychology (New Brunswick, N.J.), 1-13. Advance online publication. https://doi. org/10.1007/s12144-020-01205-1.

Ong, E., \& Thompson, C. (2019). The importance of coping and emotion regulation in the occurrence of suicidal behavior. Psychological Reports, 122(4), 1192-1210. https://doi.org/10.1177/0033294118781855.

Orom, H., Nelson, C. J., Underwood 3rd, W., Homish, D. L., \& Kapoor, D. A. (2015). Factors associated with emotional distress in newly diagnosed prostate cancer patients. Psycho-Oncology, 24(11), 1416-1422. https://doi.org/10.1002/pon.3751.

Pfefferbaum, B., \& North, C. S. (2020). Mental Health and the Covid-19 Pandemic. The New England journal of medicine, 383(6), 510-512. https://doi.org/10.1056/NEJMp2008017.

Pressman, S. D., Jenkins, B. N., \& Moskowitz, J. T. (2019). Positive affect and health: What do we know and where next should we go? Annual Review of Psychology, 70(1), 627-650. https://doi.org/10.1146/annurevpsych-010418-102955.

Qiu, J., Shen, B., Zhao, M., Wang, Z., Xie, B., \& Xu, Y. (2020). A nationwide survey of psychological distress among Chinese people in the COVID-19 epidemic: Implications and policy recommendations. General psychiatry, 33(2), e100213. https://doi.org/10.1136/gpsych-2020-100213.

Ridner, S. H. (2004). Psychological distress: Concept analysis. Journal of Advanced Nursing, 45(5), 536-545. https://doi.org/10.1046/j.1365-2648.2003.02938.x.

Satici, B., Gocet-Tekin, E., Deniz, M. E., \& Satici, S. A. (2020). Adaptation of the Fear of COVID-19 Scale: its association with psychological distress and life satisfaction in Turkey. International Journal of Mental Health and Addiction. Advance online publication. https://doi.org/10.1007/s11469-020-00294-0.

Scheier, M. F., Carver, C. S., \& Bridges, M. W. (1994). Distinguishing optimism from neuroticism (and trait anxiety, self-mastery, and self-esteem): a re-evaluation of the Life Orientation Test. Journal of Personality and Social Psychology, 67, 1063-1078.

Schumacker, R. E., \& Lomax, R. G. (2016). A beginner's guide to structural equation modeling (4th ed.). Routledge. https://doi.org/10.4324/9780203851319.

Shi, L., Lu, Z.-A., Que, J.-Y., Huang, X.-L., Liu, L., Ran, M.-S., Gong, Y. M., Yuan, K., Yan, W., Sun, Y. K., Shi, J., Bao, Y. P., \& Lu, L. (2020). Prevalence of and risk factors associated with mental health symptoms among the general population in China during the coronavirus disease 2019 pandemic. JAMA Network Open, 3(7), e2014053. https://doi.org/10.1001/jamanetworkopen.2020.14053.

Smith, B. W., Dalen, J., Wiggins, K., Tooley, E., Christopher, P., \& Bernard, J. (2008). The brief resilience scale: assessing the ability to bounce back. International Journal of Behavioral Medicine, 15(3), 194-200. https:// doi.org/10.1080/10705500802222972.

Smith, J. L., \& Hanni, A. A. (2019). Effects of a savoring intervention on resilience and well-being of older adults. Journal of Applied Gerontology, 38(1), 137-152. https://doi.org/10.1177/0733464817693375.

Snoek, F. J., Bremmer, M. A., \& Hermanns, N. (2015). Constructs of depression and distress in diabetes: time for an appraisal. The Lancet Diabetes and Endocrinology, 3(6), 450-460. https://doi.org/10.1016/S22138587(15)00135-7.

Spitzer, R. L., Kroenke, K., Williams, J. B. W., \& Löwe, B. (2006). A brief measure for assessing generalized anxiety disorder: The GAD-7. Archives of Internal Medicine, 166(10), 1092-1097. https://doi.org/10.1001/ archinte.166.10.1092.

Tabachnick, B. G., \& Fidell, L. S. (2014). Using multivariate statistics (6th ed.). Pearson Education.

Taylor, S., Landry, C. A., Paluszek, M. M., Fergus, T. A., McKay, D., \& Asmundson, G. J. G. (2020). Development and initial validation of the COVID Stress Scales. Journal of Anxiety Disorders, 7, 102232. https://doi.org/10.1016/j.janxdis.2020.102232.

Vitek, L., Rosenzweig, M. Q., \& Stollings, S. (2007). Distress in patients with cancer: definition, assessment, and suggested interventions. Clinical Journal of Oncology Nursing, 11, 413-418.

Wang, C., Pan, R., Wan, X., Tan, Y., Xu, L., Ho, C. S., \& Ho, R. C. (2020). Immediate psychological responses and associated factors during the initial stage of the 2019 coronavirus disease (COVID-19) epidemic among the general population in China. International Journal of Environmental Research and Public Health, 17(5), 1729. https://doi.org/10.3390/ijerph17051729. 
Wichman, C. L., Ehlers, S. L., Wichman, S. E., Weaver, A. L., \& Coddington, C. (2011). Comparison of multiple psychological distress measures between men and women preparing for in vitro fertilization. Fertility and Sterility, 95(2), 717-721. https://doi.org/10.1016/j.fertnstert.2010.09.043.

Worldometer. (2021). Coronavirus cases. Retrieved March 10, 2021, from: https:/www.worldometers.info/ coronavirus/.

WU, X., Nazari, N., \& Griffiths, M. D. (2020). Fear of Covid-19 and COVID-19 anxiety predict cyberchondria: Intolerance of uncertainty and anxiety sensitivity as potential risk factors. Journal of Medical Internet Research, Advance Online Publication. https://doi.org/10.2196/26285.

Yang, H., \& Ma, J. (2020). How an epidemic outbreak impacts happiness: factors that worsen (vs. protect) emotional well-being during the coronavirus pandemic. Psychiatry Research, 289, 113045. https://doi.org/ 10.1016/j.psychres.2020.113045.

Publisher's Note Springer Nature remains neutral with regard to jurisdictional claims in published maps and institutional affiliations. 